\title{
Desaturation index versus isotopically measured de novo lipogenesis as an indicator of acute systemic lipogenesis
}

\author{
Scott V Harding ${ }^{1 *}$, Kevin P Bateman ${ }^{2}$, Brian P Kennedy ${ }^{3,6}$, Todd C Rideout ${ }^{4}$ and Peter JH Jones ${ }^{5^{*}}$
}

\begin{abstract}
Background: High carbohydrate feeding is known to increase plasma triglycerides as well as hepatic de novo lipogenesis (DNL) and may be implicated in the development of hepatic insulin resistance and fatty liver. Unfortunately, it is technically challenging to determine what proportion of circulating plasma triglycerides have been derived from the newly synthesized fatty acids in the postprandial period. The aims of this study were to 1) characterize the changes in the plasma postprandial total fatty acid pool in beagles following the consumption of meals containing 44\% (Control) and 74\% (High Sucrose) carbohydrate and 2) determine if changes in plasma fatty acid concentration and delta-9 desaturation index (DI) would be useful as simple and easy to measure biomarkers of systemic DNL.

Findings: No differences in plasma total palmitic acid (16:0), stearic acid (18:0) and oleic acid (18:1) concentrations or delta-9 DI for the total 18:0 and 18:1 pools between High Sucrose and Controls were observed. However, newly synthesized $16: 0(2.6 \pm 0.2 \%$ vs. $8.8 \pm 2.0 \% ; p=0.016), 18: 0(0.93 \pm 0.2 \%$ vs. $4.1 \pm 1.7 \% ; p=0.007)$ and $18: 1(0.29 \pm 0.09 \%$ vs. $3.5 \pm 1.2 \% ; p=0.017$ ) were higher in High Sucrose versus Control animals, respectively. Also, the delta-9 DI for the newly synthesized 18:0 and 18:1 pools was higher at 2 and 6 hours postprandial, with a pattern of change which supports the increased stearoyl-CoA desaturase (SCD-1) activity following high carbohydrate feeding followed by a down regulation of this enzyme.
\end{abstract}

Conclusions: Our data show that high sucrose meals increase the relative contribution of systemic DNL produced fatty acids to the total postprandial plasma fatty acid pool. These data also show that a different pattern of both fatty acid synthesis and disposal occurs depending on energy and macronutrient profile of the meal. These changes are in spite of no observable changes in the plasma concentrations or ratios of the total fatty acid pool opposed to the observed changes in the newly synthesized fatty acid pool.

\section{Background}

Diets high in carbohydrate are known to increase serum triglycerides (TG) [1-3] but the overall contribution of these diets to adiposity appears to be limited [4-6]. Overfeeding with simple carbohydrates to the point of exceeding total energy expenditure will yield higher absolute de novo lipogenesis (DNL) [7], but such situations are not normal over the long term in humans [8]. Therefore, carbohydrate induced DNL may not increase fat

\footnotetext{
*Correspondence: scott.harding@kcl.ac.uk; peter.jones@umanitoba.ca

'Diabetes and Nutritional Sciences Division, King's College London,

150 Stamford Street, London SE1 9NH, UK

${ }^{5}$ Richardson Centre for Functional Foods and Nutraceuticals, University of Manitoba, Winnipeg R3T 6C5, MB, Canada

Full list of author information is available at the end of the article
}

mass and adiposity to any great extent but the effect on hepatic lipid metabolism may be important in the development of hepatic insulin resistance and its related morbidities [9-11]. Hepatic insulin resistance may in fact be a protective mechanism which initiated by the liver during periods of excess energy substrate metabolism [12]. However, the contribution of simple carbohydrate to DNL during such periods invariably contributes to excess hepatic lipid production while rates of $\beta$-oxidation are generally reduced due to the increased malonyl-CoA concentrations produced via glycolysis and used as a substrate for DNL. Depending on the carbohydrate load consumed, the resulting DNL and TG production may exceed the VLDL secretion capacity resulting in increased 
liver fat content. Therefore, high carbohydrate diets especially those high in simple sugars - are of particular interest the development of fatty liver diseases and hepatic insulin resistance.

Changes in hepatic lipid metabolism can be assessed by the changes in plasma lipid pools - namely the fatty acid and sterol pools. Because the main driver of the serum TG levels following high carbohydrate feeding tends to be DNL [13], changes in the relative proportion of newly synthesized fatty acids in the plasma are reflective of the DNL contribution to postprandial lipemia. Because of this direct relationship between dietary carbohydrate and the rate of postprandial DNL there is much interest in how this relationship contributes to the development of lipemia [14], obesity [2] and diabetes [15].

Overfeeding with both excess calories and simple carbohydrate is a very strong promoter of hepatic DNL [9-11] and understanding its impact on hepatic lipid metabolism and associated plasma biomarkers is important for understanding the development of hepatic insulin resistance. Therefore, the purpose of this study was to characterize the changes in the plasma postprandial total fatty acid pool in response to a high calorie simple carbohydrate meal. Our aim was to quantify plasma total fatty acid concentrations and hepatic fatty acid synthesis using isotopic techniques. We hypothesized that animals fed moderately excess calories and high sucrose would have higher plasma 16:0, 18:0 and 18:1 concentrations, higher desaturation indexes and proportion of newly synthesized fatty acids compared to controls. Our rationale for the examining the DI in relation to DNL is that while the terminal product of DNL is palmitate one of the preferred substrate in the synthesis of triglyceride is 18-carbon monounsaturated fatty acids [16]. Therefore, an increase in DNL may also alter the desaturation index of the plasma fatty acids proportional to rate of DNL and triglyceride synthesis. Ideally, the changes in fatty acid concentration and delta-9 DI would be then useful as cheap and easy to measure biomarkers of hepatic DNL if the patterns of change were confirmed by the isotopic data.

\section{Methods}

\section{Experimental animals and diets}

All procedures for in vivo experiments were approved by the Animal Care Committee at the Merck Frosst Centre for Therapeutic Research (Kirkland, Quebec, Canada) and were performed according to guidelines established by the Canadian Council on Animal Care [17]. Twelve adult male beagles from the Merck Frosst Centre for Therapeutic Research beagle colony, previously maintained on normal dog chow (Teklad Global Diet 2025, Harlan Teklad, Madison, WI), were randomized to receive a high sucrose meal (High Sucrose; Table 1)
Table 1 High sucrose test meal composition

\begin{tabular}{lll}
\hline & Composition \\
\cline { 2 - 3 } Ingredients & Amount (g) & Energy (Kcal) \\
\hline Casein & 300 & 800 \\
DL-Methionine & 48 & 12 \\
Corn starch, pre-gelatinized & 75 & 192 \\
Maltodextrin (Lodex 10) & 750 & 300 \\
Sucrose & 50 & 3000 \\
Cellulose & 50 & 0 \\
Soybean oil & 50 & 450 \\
Mineral mix S70003 & 10 & 0 \\
Vitamin mix V90003 & 2 & 40 \\
Choline Bitartrate & 1238 & 0 \\
Total & & 4794 \\
\hline
\end{tabular}

providing $3.9 \mathrm{kcal} / \mathrm{g}$ of diet with $74 \%$ of calories from carbohydrate or normal chow meal (Control) providing $3.5 \mathrm{kcal} / \mathrm{g}$ of diet with $42 \%$ of calories from carbohydrate (Table 2). Dogs receiving the high sucrose diet consumed a $400 \mathrm{~g}$ meal while those receiving the normal chow consumed a $250 \mathrm{~g}$ meal - $1560 \mathrm{kcal}$ versus $875 \mathrm{kcal}$. Once meals were consumed each dog received $10 \mathrm{ml} / \mathrm{kg}$ body weight of deuterium oxide $\left(\mathrm{D}_{2} \mathrm{O} ; 99.9 \%\right.$ APE, CDN Isotopes, Pointe Claire, Quebec, Canada) administered by syringe. The syringes were then filled with $20 \mathrm{ml}$ of distilled water and administered to the dog immediately after isotope dosing. Blood samples were taken, from a temporarily placed cannula, 1 hour before and $1,2,4,6,8$ hours post $\mathrm{D}_{2} \mathrm{O}$ administration to measure the incorporation of deuterium into newly synthesized 16:0, 18:0 and 18:1. Only blood samples were collected for this experiment, there were no adverse events during the protocol and no animals were euthanized in this experiment.

\section{Lipid extraction and fatty acid methyl ester conversion}

Lipids were extracted and fatty acids converted to their methyl ester by standard procedures, previously reported [18]. Briefly, $0.5 \mathrm{ml}$ of EDTA plasma and $125 \mu \mathrm{l}$ of internal standard (heptadecanoic acid) were added to $8 \mathrm{ml}$ of methanol followed by heating in $55^{\circ} \mathrm{C}$ water bath for 15 minutes. Hexane:chloroform $(4: 1, \mathrm{v} / \mathrm{v} ; 24 \mathrm{ml})$ was then added followed by vortexing. Boron trifloridemethanol:hexane:methanol $(7: 6: 7 \mathrm{v} / \mathrm{v} / \mathrm{v} ; 1 \mathrm{ml})$ was added to the dried lipid extract and fatty acid methyl esters were recovered following incubation at $100^{\circ} \mathrm{C}$ for 1 hour [18]. Samples were transferred to GC autosampler vials and stored at $-80^{\circ} \mathrm{C}$ for analysis.

\section{Plasma fatty acid concentration and desaturation index}

Fatty acid concentrations for palmitic, stearic and oleic acids were determined by gas chromatography with 
Table 2 Macronutrient composition of intervention and control meals

\begin{tabular}{|c|c|c|c|c|}
\hline \multirow[t]{2}{*}{ Macronutrient } & \multicolumn{2}{|l|}{ High sucrose } & \multicolumn{2}{|l|}{ Control $^{1}$} \\
\hline & $\%$ composition (wt/wt) & $\%$ energy (\% of total $\mathrm{kcal}$ ) & $\%$ composition (wt/wt) & $\%$ energy (\% of total kcal) \\
\hline Protein & 16 & 17 & 26 & 32 \\
\hline Carbohydrate & 71 & 74 & 61 & 42 \\
\hline Fat & 4 & 9 & 11 & 26 \\
\hline Other & 9 & $\mathrm{n} / \mathrm{a}$ & 2 & $\mathrm{n} / \mathrm{a}$ \\
\hline Macronutrient total & 100 & 100 & 100 & 100 \\
\hline Energy density (kcal/g) & 3.9 & & 3.5 & \\
\hline
\end{tabular}

${ }^{1}$ Commerical dog diet; Teklad Global 25\% Protein Dog Diet-2025; Supplier: Harlan Teklad.

flame ionization (Agilent $6890 \mathrm{~N}$, Mississauga, Canada). FAME were separated using a Supleco 2380 (30 m) with initial temperature of $50^{\circ} \mathrm{C}$ for $1 \mathrm{~min}$ then to $170^{\circ} \mathrm{C}$ (rate $40^{\circ} \mathrm{C} / \mathrm{min}$ ) then to $220^{\circ} \mathrm{C}$ (rate $8^{\circ} \mathrm{C}$ ). Heptadecanoic acid was used as an internal standard and retention times were confirmed by using appropriate pure standards for each for each fatty acid. The $\Delta-9$ desaturation index of the plasma fatty acids was calculated as the ratio of the total oleic acid pool to the total stearic acid pool [19]. Fatty acid concentrations were expressed as $\mu \mathrm{g}$ per $\mathrm{ml}$ of plasma.

\section{Fatty acid methyl ester deuterium incorporation}

FAME deuterium incorporation was determined using GC separation on a Supleco 2380 column $(30 \mathrm{~m} \times$ $0.25 \mathrm{~mm}$ i.d. $\times 25 \mu \mathrm{m}$ film thickness) followed by thermal conversion (pyrolysis) to hydrogen gas at $1450^{\circ} \mathrm{C}$ online and subsequent isotope ratio of deuterium:hydrogen measured via isotope ratio mass spectrometry (Delta V Plus, Thermo Electron Corporation, Massachusetts, USA). Deuterium enrichment was expressed as delta per mil $\left(\delta^{2} \mathrm{H} \%\right.$ o) versus VSMOW was then converted to atom percent excess (APE).

\section{Statistical analysis}

Plasma fatty acid concentrations, desaturation index and newly synthesized fatty acid concentrations were analyzed by multivariate analysis of variance where each values at each time point were treated as separate dependant variables and diet was designated as the independent variable. Data was analyzed using SPSS (version 21 , IBM, Inc), 6/6 dogs per group used in statistical analysis and all values are expressed as means \pm SEM.

\section{Findings}

Plasma fatty acid methyl ester concentration and desaturation index

Despite the overfeeding of sucrose there were no differences in postprandial plasma fatty acid concentrations for palmitic, stearic or oleic acids over the 8 hour post meal timeframe (Figure 1). Furthermore, the delta-9 DI did not differ for the total oleic and stearic acid pools (existing + dietary + newly synthesized) across the time points of the postprandial study period (Figure 2A) however the delta-9 DI for the newly synthesized fatty acids was different at hour 2 and hour 6 (Figure 2B). The pattern of change for the delta-9 DI of newly synthesized fatty acids was that of steadily decreasing.

\section{Newly synthesized plasma fatty acids}

The amount of newly synthesized palmitic, stearic and oleic acid - expressed in terms of concentration - were higher following the high sucrose feeding versus control chow meal at each time point in the postprandial period (Figure 3A-3C). The total percent newly synthesized palmitic $(2.6 \pm 0.2 \%$ vs. $8.8 \pm 2.0 \% ; \mathrm{p}=0.016)$, stearic $(0.93 \pm 0.2 \%$ vs. $4.1 \pm 1.7 \% ; \mathrm{p}=0.007)$ and oleic $(0.29 \pm 0.09 \%$ vs. $3.5 \pm 1.2 \%$; $\mathrm{p}=0.017$ ) was also higher in the high sucrose fed animals, respectively.

\section{Discussion}

Our objective in this study was to determine the effect of a high sucrose feeding on the production of liver derived newly synthesized fatty acids appearing in the plasma during the postprandial period and whether the delta-9 DI would serve as a useful biomarker of acute DNL. Our data show that dogs, previously unexposed to high sucrose diets, have significantly higher hepatic DNL as measured by newly synthesized fatty acids appearing in the plasma pool. In fact, dogs consuming the high sucrose had approximately 2.8-fold, 3.4-fold and 11-fold higher production of palmitic, stearic and oleic acid, respectively, over an 8 hour postprandial period. However, neither the plasma fatty acid concentration nor the delta-9 DI for the total stearic and oleic acid pools differed by treatment. However, the delta-9 DI for the newly synthesized stearic and oleic acid pools did differ at hour 2 and hour 6 of the postprandial period. This observation and the pattern of a decreasing delta-9 DI for the newly synthesized mirrors what would be expected based on an increased SCD-1 activity following a high carbohydrate meal [20].

A temporal pattern of postprandial DNL has been described by Timlin and Parks (2005) in humans which 

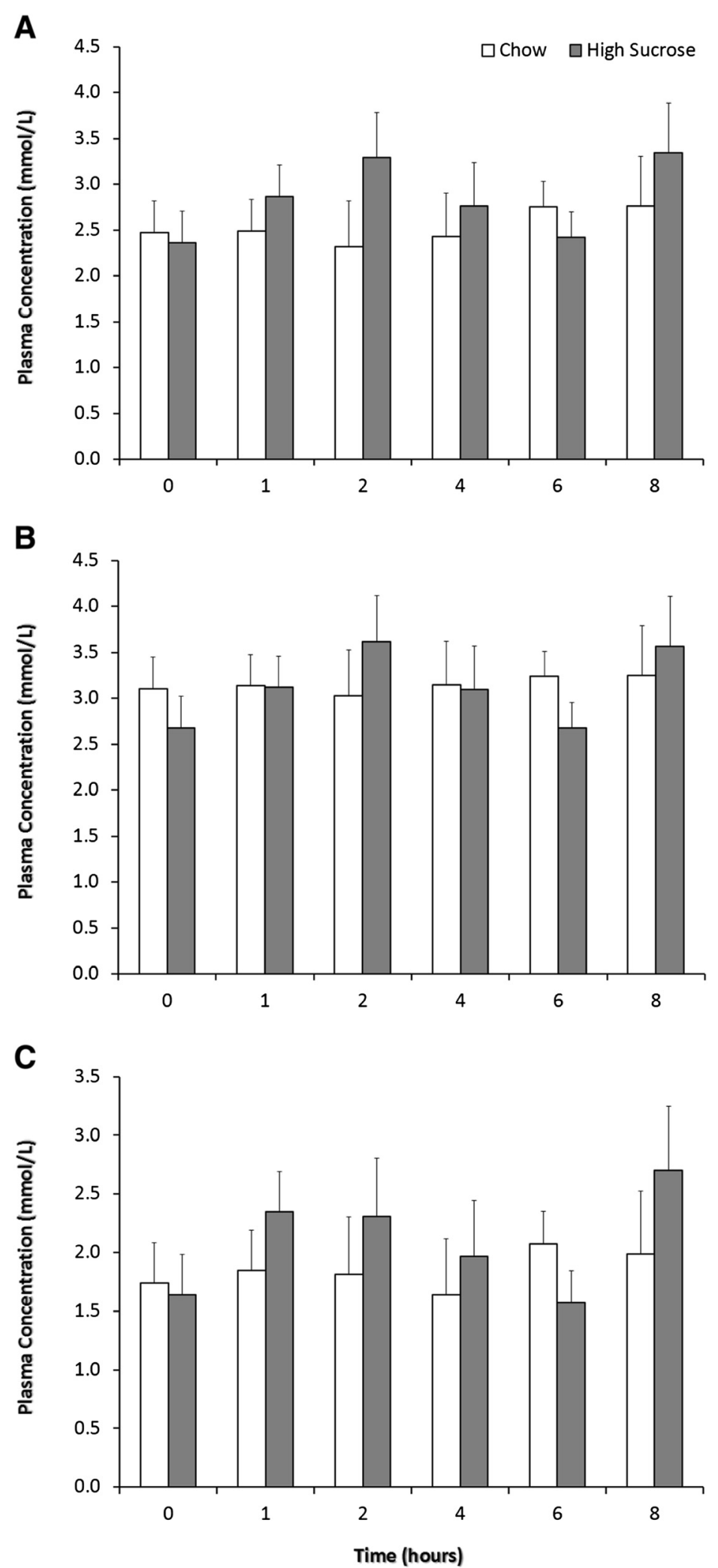

Figure 1 (See legend on next page.) 
(See figure on previous page.)

Figure 1 The effect of high sucrose consumption on plasma fatty acid concentrations. Beagles consuming either high sucrose meal providing $3.9 \mathrm{kcal} / \mathrm{g}$ of diet with 74\% of calories from carbohydrate (High Sucrose; $400 \mathrm{~g} ; 1560 \mathrm{kcal}$ ) or normal chow diet providing $3.5 \mathrm{kcal} / \mathrm{g}$ of diet with 44\% of calories from carbohydrate (Control; $250 \mathrm{~g} ; 875 \mathrm{kcal}$ ). A) Palmitic acid plasma concentrations, B) stearic acid plasma concentrations and $\mathbf{C}$ ) oleic acid concentrations. Data are expressed as means $\pm \mathrm{SEM} ; \mathrm{n}=6$.

clearly have a steep departure from baseline TG concentrations and synthesis from an overnight fast that is compounded by meal frequency [4]. Concentrations of TG were not measured in this study and our plasma fatty acid concentrations fluctuated, but a pattern similar to that observed by Timlin and Parks for TG concentrations was not seen in these data over the 8 hours postprandial period [4]. Using the changes in the lipogenic fatty acid products may be useful biomarkers of hepatic DNL in response to high sucrose feeding because 1)
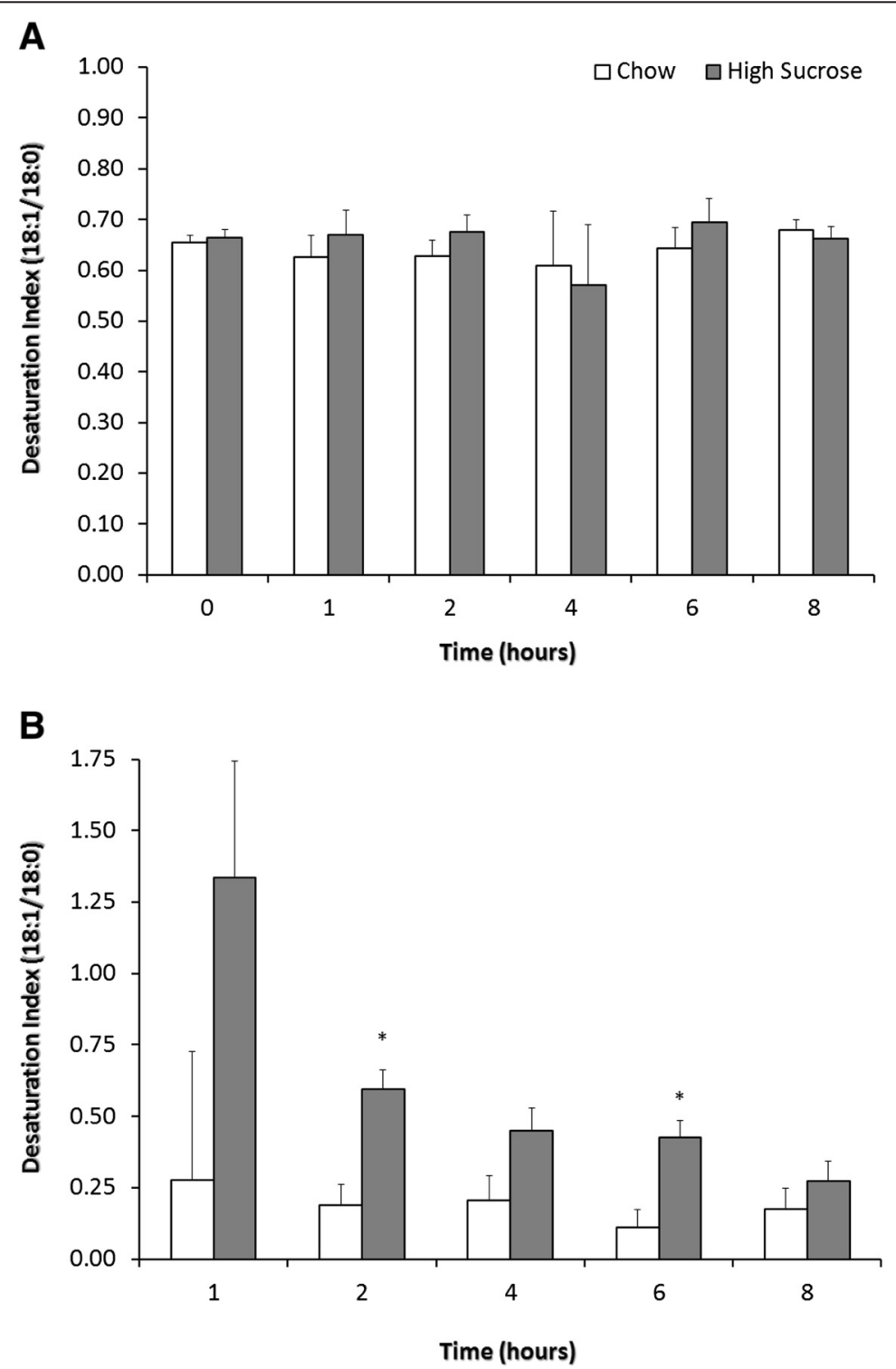

Figure 2 The effect of high sucrose consumption on plasma $\Delta-\mathbf{9}$ desaturation index. The delta-9 desaturation index is calculated as the ratio of the concentration of oleic acid (18:1) to stearic acid (18:0). A) The delta-9 desaturation index for total 18:1 and 18:0 pools from hours 0-8 of the postprandial period. B) The delta-9 desaturation index for newly synthesized 18:1 and 18:0 pools from hours 1-8 of the postprandial period. The pattern of change from a high desaturation index to low is indicative of the increased SCD-1 activity following a high carbohydrate meal. Data are expressed as means \pm SEM; $n=6 .{ }^{*}$ indicates $p<0.036$ at each time point for High Sucrose versus Control. 

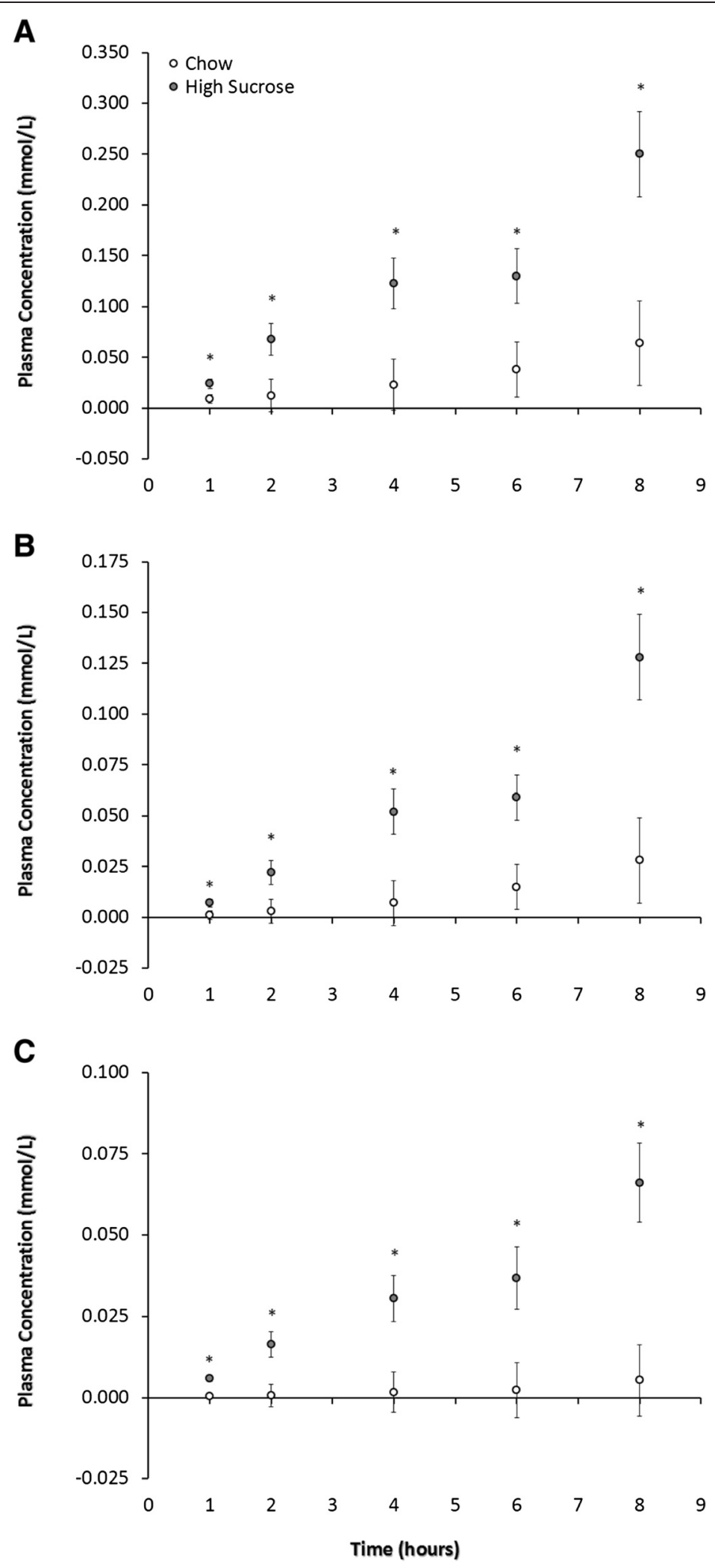

Figure $\mathbf{3}$ (See legend on next page.) 
(See figure on previous page.)

Figure 3 The effect of high sucrose consumption on indicators of hepatic DNL. Newly synthesized palmitic, stearic and oleic acid (expressed as concentration) at each time point in the postprandial period. A) Plasma newly synthesized palmitic acid, normalized to baseline natural enrichment. The proportion and absolute concentration of newly synthesized palmitic acid was higher at each time point measured in the postprandial period. B) Plasma newly synthesized stearic acid, normalized to baseline natural enrichment. The proportion and absolute concentration of newly synthesized stearic acid was higher at each time point measured in the postprandial period. C) Plasma newly synthesized oleic acid, normalized to baseline natural enrichment. The proportion and absolute concentration of newly synthesized oleic acid was higher at each time point measured in the postprandial period. Data are expressed as means $\pm \mathrm{SEM} ; \mathrm{n}=6 .{ }^{*}$ indicates $\mathrm{p}<0.036$ at each time point for High Sucrose versus Control.

higher levels of newly synthesized stearic acid indicates an increase in the elongation of palmitic acid by the hepatic fatty acid elongase-5 (elovl5) [21,22], and 2) the desaturation of stearic acid to oleic acid, via hepatic stearoyl-CoA desaturase 1 (SCD-1) [23] would also be increased. Unlike Timlin and Parks, we examined the contribution of total newly synthesized plasma fatty acids to the postprandial plasma fatty acid pool in order to simplify our analysis but saw no differences in the plasma palmitic, stearic and oleic acid concentrations and no differences in the delta-9 desaturation index.

As stated by Murphy [24], the use of deuterium incorporation and GC-IRMS is an excellent and sensitive technique to determine differences in fractional lipogenesis, but requires the determination of the specific fraction of deuterium which are introduced into the molecules understudy to precisely calculate absolute DNL. The model we present here demonstrates how the use of deuterium incorporation and GC-IRMS allow for the precise detection of label entry into the pools in question, even when those pools are extremely small. Also, the high sensitivity of IRMS and rapid distribution of ${ }^{2} \mathrm{H}$-label throughout total body water negates the need for long infusion to achieve isotopic steady state. Therefore, this isotopic technique not only provides a means to study differences in fractional DNL, but also the changes in DNL products through elongation and desaturation.

Two key limitations of this study are the multiple differences in the energy and composition of the meals and the inability to quantitate the contribution of all the tissues contributing to the total newly synthesized fatty acid pool (e.g. hepatic, adipose and intestinal). Firstly, the fatty acid composition, total carbohydrate load and total energy intake all exert an effect on the outcome measures presented here [25]. While this limits the ability to draw definitive conclusions as to the mechanisms responsible for the differing patterns of DNL. Similarly, the contribution of newly synthesized fatty acids by different tissues to the total fatty acid pool may indeed be directly affected by these dietary difference but there is no way to capture this information using the deuterium incorporation technique as used here. While the majority of the newly synthesized fatty acids are likely from hepatic DNL the consequences of having multiple difference in the meal compositions could impact the sources contributing to the total pool of newly synthesized fatty acids.

\section{Conclusion}

In conclusion, our data illustrate that overfeeding with simple carbohydrates versus a normal basal diet in a single meal increases the relative contribution of total plasma fatty acids from DNL in the postprandial period. These data would also seem to indicate different patterns of both fatty acid synthesis and disposal in the short term following meals of high simple carbohydrate content. Unfortunately, the changes observed in the isotopic data were not observed in the fatty acid concentrations or the delta-9 DI. While the delta-9 DI of the total stearic and oleic acid pools did not prove to be a useful biomarker these data do illustrate the effectiveness of the deuterium incorporation technique for discriminating the very small changes in postprandial lipogenesis observed between treatments in this study and as a useful tool for potentially quantitating the activity of SCD-1 in the early postprandial period.

\section{Abbreviations}

DNL: de novo lipogenesis; DI: Desaturation index; ELOVL5: Hepatic fatty acid elongase-5; FAME: Fatty acid methyl esters; GC-IRMS: Gas chromatography isotope ratio mass spectrometry; SCD-1: Stearoyl-CoA desaturase 1;

TG: Triglycerides.

\section{Competing interests}

KBP is currently employed by Merck; BPK was employed by Merck Frosst at the time this research was conducted; $\mathrm{PJHJ}$ received consultant fees, honoraria, travel funding, or research support from Merck and Merck Frosst. The authors declare that there are no competing interests regarding the publication of this manuscript.

\section{Authors' contributions}

SVH conceived the study, conducted the analysis, wrote the first draft of the manuscript and is responsible for the content of the manuscript. KPB and BPK contributed to the study design, directed the animal study and sample collection and edited subsequent drafts of the manuscript. TCR contributed to the data analysis and helped draft the manuscript. PJJ conceived the study, contributed to the study design, coordinated the research and edited the manuscript. All authors read and approved the final manuscript.

\section{Acknowledgements}

The authors would like to thank Mrs Ruifang Wang for her contribution to sample analysis.

\section{Funding}

The study and analysis was funded by an unrestricted research grant from Merck. Funding for the preparation of this manuscript for SVH was provided 
by King's College London and University of Manitoba, KBP and BPK by Merck Frosst Center for Therapeutic Research, TCR by University at Buffalo and PJHJ by University of Manitoba. The article-processing charge was paid for by King's College London.

\section{Author details}

'Diabetes and Nutritional Sciences Division, King's College London, 150 Stamford Street, London SE1 9NH, UK. ${ }^{2}$ Department of Pharmacokinetics, Pharmacodynamics and Drug Metabolism, Merck, One Merck Drive, Whitehouse Station, NJ 08889, USA. ${ }^{3}$ Kaneq Pharma, Montreal, QC, Canada. ${ }^{4}$ Department of Exercise and Nutrition Sciences, University at Buffalo, Buffalo, NY 14214, USA. ${ }^{5}$ Richardson Centre for Functional Foods and Nutraceuticals, University of Manitoba, Winnipeg R3T 6C5, MB, Canada. ${ }^{6}$ Previously at Department of Biochemistry and Molecular Biology at the Merck Frosst Center for Therapeutic Research, Montreal, QC, Canada.

Received: 13 June 2014 Accepted: 13 February 2015 Published online: 23 February 2015

\section{Reference}

1. Mensink RP, Katan MB. Effect of monounsaturated fatty acids versus complex carbohydrates on high-density lipoproteins in healthy men and women. Lancet. 1987;1 (8525):122-5.

2. Stanhope KL, Havel PJ. Fructose consumption: potential mechanisms for its effects to increase visceral adiposity and induce dyslipidemia and insulin resistance. Curr Opin Lipidol. 2008;19(1):16-24.

3. Appel LJ, Sacks FM, Carey VJ, Obarzanek E, Swain JF, Miller 3rd ER, et al. Effects of protein, monounsaturated fat, and carbohydrate intake on blood pressure and serum lipids: results of the OmniHeart randomized trial. JAMA. 2005;294(19):2455-64. doi:10.1001/jama.294.19.2455.

4. Timlin MT, Parks EJ. Temporal pattern of de novo lipogenesis in the postprandial state in healthy men. Am J Clin Nutr. 2005;81(1):35-42.

5. Parks EJ, Krauss RM, Christiansen MP, Neese RA, Hellerstein MK. Effects of a low-fat, high-carbohydrate diet on VLDL-triglyceride assembly, production, and clearance. J Clin Invest. 1999;104(8):1087-96.

6. Marques-Lopes I, Ansorena D, Astiasaran I, Forga L, Martinez JA. Postprandial de novo lipogenesis and metabolic changes induced by a high-carbohydrate low-fat meal in lean and overweight men. Am J Clin Nutr. 2001;73(2):253-61.

7. McDevitt RM, Bott SJ, Harding M, Coward WA, Bluck LJ, Prentice AM. De novo lipogenesis during controlled overfeeding with sucrose or glucose in lean and obese women. Am J Clin Nutr. 2001;74(6):737-46.

8. Hellerstein MK. No common energy currency: de novo lipogenesis as the road less traveled. Am J Clin Nutr. 2001;74(6):707-8.

9. Lee JJ, Lambert JE, Hovhannisyan Y, Ramos-Roman MA, Trombold JR, Wagner DA, et al. Palmitoleic acid is elevated in fatty liver disease and reflects hepatic lipogenesis. Am J Clin Nutr. 2015;101(1):34-43. doi:10.3945/ajen.114.092262.

10. Diraison F, Moulin P, Beylot M. Contribution of hepatic de novo lipogenesis and reesterification of plasma non esterified fatty acids to plasma triglyceride synthesis during non-alcoholic fatty liver disease. Diabetes Metab. 2003;29(5):478-85.

11. Wilke MS, French MA, Goh YK, Ryan EA, Jones PJ, Clandinin MT. Synthesis of specific fatty acids contributes to VLDL-triacylglycerol composition in humans with and without type 2 diabetes. Diabetologia. 2009;52(8):1628-37. doi:10.1007/s00125-009-1405-9.

12. Agius L. High-carbohydrate diets induce hepatic insulin resistance to protect the liver from substrate overload. Biochem Pharmacol. 2013;85(3):306-12. doi:10.1016/j.bcp.2012.09.019.

13. Chong MF, Fielding BA, Frayn KN. Mechanisms for the acute effect of fructose on postprandial lipemia. Am J Clin Nutr. 2007;85(6):1511-20.

14. Karpe F, de Faire U, Mercuri M, Bond MG, Hellenius ML, Hamsten A. Magnitude of alimentary lipemia is related to intima-media thickness of the common carotid artery in middle-aged men. Atherosclerosis. 1998;141(2):307-14.

15. Tomkin GH. Targets for intervention in dyslipidemia in diabetes. Diabetes Care. 2008;31 Suppl 2:S241-8.

16. Moon YA, Ochoa CR, Mitsche MA, Hammer RE, Horton JD. Deletion of ELOVL6 blocks the synthesis of oleic acid but does not prevent the development of fatty liver or insulin resistance. J Lipid Res. 2014;55(12):2597-605. doi:10.1194/jl.M054353.
17. Canadian Council on Animal Care. Accessed on; Available from: http://www.ccac.ca.

18. Morrison WR, Smith LM. Preparation of Fatty Acid Methyl Esters and Dimethylacetals from Lipids with Boron Fluoride-Methanol. J Lipid Res. 1964;5:600-8.

19. Jiang G, Li Z, Liu F, Ellsworth K, Dallas-Yang Q, Wu M, et al. Prevention of obesity in mice by antisense oligonucleotide inhibitors of stearoyl-COA desaturase-1. J Clin Invest. 2005;115(4):1030-8.

20. Chong MF, Hodson L, Bickerton AS, Roberts R, Neville M, Karpe F, et al. Parallel activation of de novo lipogenesis and stearoyl-CoA desaturase activity after $3 \mathrm{~d}$ of high-carbohydrate feeding. Am J Clin Nutr. 2008;87(4):817-23.

21. Wang Y, Torres-Gonzalez M, Tripathy S, Botolin D, Christian B, Jump DB. Elevated hepatic fatty acid elongase-5 (elovl-5) activity affects multiple pathways controlling hepatic lipid and carbohydrate composition. J Lipid Res. 2008;49(7):1538-52.

22. Wang Y, Botolin D, Christian B, Busik J, Xu J, Jump DB. Tissue-specific, nutritional, and developmental regulation of rat fatty acid elongases. J Lipid Res. 2005;46(4):706-15. doi:10.1194/jlr. M400335-JLR200.

23. Enoch HG, Catala A, Strittmatter P. Mechanism of rat liver microsomal stearyl-CoA desaturase. Studies of the substrate specificity, enzyme-substrate interactions, and the function of lipid. J Biol Chem. 1976;251(16):5095-103.

24. Murphy EJ. Stable isotope methods for the in vivo measurement of lipogenesis and triglyceride metabolism. J Anim Sci. 2006;84(Suppl):E94-104.

25. Oosterveer MH, van Dijk TH, Tietge UJ, Boer T, Havinga R, Stellaard F, et al. High fat feeding induces hepatic fatty acid elongation in mice. PLoS One. 2009;4(6):e6066. doi:10.1371/journal.pone.0006066.

\section{Submit your next manuscript to BioMed Central and take full advantage of:}

- Convenient online submission

- Thorough peer review

- No space constraints or color figure charges

- Immediate publication on acceptance

- Inclusion in PubMed, CAS, Scopus and Google Scholar

- Research which is freely available for redistribution

Submit your manuscript at www.biomedcentral.com/submit
C BioMed Central 